\title{
The Lexical Bias Effect during Speech Production in the First and Second Language
}

\author{
Wouter P. J. Broos, Wouter Duyck, \& Robert J. Hartsuiker \\ Department of Experimental Psychology, Ghent University
}

\begin{abstract}
Author Note
Wouter P. J. Broos, Department of Experimental Psychology, Ghent University

Wouter Duyck, Department of Experimental Psychology, Ghent University

Robert J. Hartsuiker, Department of Experimental Psychology, Ghent University

This paper received funding from the special research fund of Ghent University (GOA - Concerted Research Action BOF13/GOA/032)

Correspondence concerning this article should be addressed to W.P.J. Broos,

Department of Experimental Psychology, Ghent University, Henri Dunantlaan 2 B-9000

Ghent, Belgium, E-mail: wouter.broos@ugent.be, Tel. +32 (0)9 2646404.
\end{abstract}




\section{Introduction}

Speech monitoring involves checking one's own speech plan before and after its execution. The importance of such a process is evident; to try to minimize the number of speech errors that are being produced. But how does this process differ in one's first language (L1) as opposed to this same process in the second language (L2) and is there even a difference to begin with? To answer these questions, we look at the lexical bias effect, which is the tendency for phonological transposition errors (e.g. 'bad salad' instead of 'sad ballad') to occur significantly more often if the switch results in existing words than in non-existing ones. Even though there is agreement on the existence of this effect, the underlying cause has not entirely been agreed upon. One explanation for the lexical bias effect is the selfmonitoring system. The monitor is a mechanism that detects and correct speech errors. These errors can be corrected after they are uttered by means of external monitoring. However, some errors are detected earlier and are corrected before they pronounced or immediately after the first part of the word via the internal monitor. An alternative explanation is that feedback between the word form and its corresponding phonemes is responsible for the effect. This feedback will increase the activation of existing words, as non-words are not included in the mental lexicon. Existing words will therefore be activated more strongly and will in turn be more likely to be uttered than non-existing ones. More recently, evidence has been presented which suggests that both the monitoring system and feedback are responsible (Hartsuiker, Corley, \& Martensen, 2005; Nooteboom \& Quené, 2008).

Thus far, only one study has focussed on the lexical bias effect in L2. In two experiments, Costa, Roelstraete, and Hartsuiker (2006) asked whether the lexical bias effect is also observed in the L2. Highly proficient bilingual Catalan-Spanish speakers performed the Spoonerisms of Laboratory-Induced Predisposition task (also called the SLIP task) in their

L2. This is a task that can be used to provoke phonological speech errors and was first used by Baars, Motley, and Mackay (1975). During this experiment, participants are presented with a series of stimulus pairs. If the participant hears a buzz, they are asked to pronounce the last stimulus pair that they saw on the screen. A few stimulus pairs that are presented before the target pair have a specific phonological construction (e.g., 'moon - loot' / 'make - lame' / 'move - lose') after which the participant is asked to pronounce the target which has the opposite phonological construction (e.g., 'leaf - meat'). All target pairs that were presented in the experiment of Costa et al. (2006) consisted of existing Spanish words and could result in existing or non-existing pairs after switching. The lexical bias effect was found in the L2. The 
second experiment focused on language interaction and asked whether the lexical bias effect would also arise in Spanish-Catalan bilinguals if the switch pair resulted in existing Catalan words while performing the task in Spanish. The lexical bias effect was also found for Catalan words, even when the task was performed in Spanish. The authors conclude that feedback of activation is present in L2 and that it can spread across languages.

It has to be noted that the participants in this study were early, highly proficient bilinguals. Moreover, all stimulus pairs that were presented were existing word pairs meaning that the influence of context lexicality (which denotes the lexicality of the presented stimulus pairs) was never tested. Consequently, the settings of the monitoring criteria could not be assessed either. Hence, the current study will test participants who are less proficient in their L2 while context lexicality will be included as a factor. The lexical bias effect will be observed in two global contexts: one where relatively little L2 words are presented (Experiment 1) and one where participants see more existing L2 words (Experiment 2). The following question can then be answered: 1. Do people who are less proficient in their L2 still show a lexical bias effect? / 2. Is it necessary for the L2 lexicon to be strongly activated in order to obtain a lexical bias effect?

\section{Experiment 1}

\section{Methods}

Participants. 48 unbalanced bilingual Dutch-English speakers (12 male / 36 female, mean age $=22.1)$ participated in the experiment. All participants were recruited at Ghent University and were monetarily compensated. Participants all reported to have normal hearing, normal or corrected-to-normal sight, and not to have dyslexia. The description of the experiment mentioned that English proficiency of the participants should be relatively good. Participants were asked to perform the English LexTALE (Lemhöfer \& Broersma, 2012) in order to objectively measure their proficiency.

Materials. 1600 monosyllabic letter strings were constructed for the current experiment. Four different types of blocks were created: a block with 200 Dutch word pairs and 200 Dutch non-word pairs (mixed L1 block), a block with 400 Dutch non-words pairs (non-lexical L1 block), a block with 200 English word pairs and 200 English non-word pairs (mixed L2 block), and a block with 400 English non-word pairs (non-lexical L2 block). Dutch 
and English non-word pairs were created by including stimuli with specific bigrams. For instance, the target non-word pair 'dift - rish' was categorized as an English non-word pair as the bigram /sh/ occurs at the coda position in English but not in Dutch. The structure of the blocks was based on that of Hartsuiker et al. (2005). Every block was divided in 20 smaller blocks, each consisting of 10 non-lexical pairs, three lexical or non-lexical filler item (depending on the lexicality of the block), one control item, five biasing pairs, and one target pair. Everything was randomised within these smaller blocks except for the biasing items. The five biasing items were randomly assigned across seven trials that preceded the target pair while two biasing pairs (with the same vowel as the target pair) always immediately preceded the target.

Each block consisted of at least 200 non-lexical pairs. Twenty non-lexical target pairs were included in each block, leading to a total of 80 target pairs per participant (since each participant saw every block once). All target pairs were non-lexical and could either result in existing or non-existing stimulus pairs after switching the initial consonants: In each block, 10 target pairs resulted in non-lexical pairs and the other 10 turned into lexical pairs. Because five biasing pairs preceded each target pair (lexical items in lexical blocks and non-lexical items in non-lexical blocks), we also included 100 non-lexical biasing items. Additionally, there were 20 control pairs per block. Control pairs had to be pronounced but were not preceded by biasing items. These items were inserted in order to obscure any phonological patterns that were present in the biasing items and target pairs. The remaining 60 stimulus pairs were either non-lexical pair fillers (in non-lexical blocks) or lexical pair fillers (in lexical blocks). The language of the lexical pairs was, of course, tailored to the language of the block. In total, $25 \%$ of the presented trials were existing word pairs (12.5\% English, $12.5 \%$ Dutch).

As mentioned, when the initial consonants were transposed the target pair could either result in a lexical or non-lexical pair. Hence, two different versions of the target pair were created while we kept the phonological structure as similar as possible. The first consonant as well as the vowel was the same in both types of outcome (e.g., the counterpart of the target pair 'duts - nuck' ('nuts - duck') was 'dufs - nush' ('nufs - dush')). The final consonants were always different from one another. Only the final two biasing pairs that immediately preceded the target pair shared the vowel as well to increase the chance of an error being made. All stimulus pairs were shaped as either CVCC (e.g., 'sich - rilk'), CVC (e.g., 'veam beal'), or CVVC (e.g., 'gaif - taip'). We ensured that none of the stimulus pairs used in the experiment consisted of Dutch-English cognates or false friends while the non-lexical pairs 
did not resemble any Dutch or English word, orthographically or phonologically. The different blocks and target pairs are placed in Appendix A.

Design. There was a total of three within-subject variables: Context (mixed vs. nonlexical), Language (L1 vs. L2), and Outcome (lexical vs. non-lexical). Since every target pair had a counterpart (one stimulus pair that resulted in an existing word pair and one in a nonexisting word pair), the target pair list can be seen as two separate parts that can be counterbalanced as well. Hence, language, context, and target list were all counterbalanced, meaning that 48 versions were created in total.

Procedure. Participants were seated in front of computer screen in a quiet room. Responses were recorded by an Edirol MP3 recorder by Roland type R-09HR, 24 bit, 96 kHz. Participants wore headphones that played back white noise of 70 decibels (following the procedure of Baars et al. (1975) and Hartsuiker et al. (2005)). By presenting white noise, participants were less able to use the external monitoring channel to monitor for errors. The participants were instructed to silently read the stimulus pairs that were presented on the screen. However, if they heard a beep over the headphones, they were asked to name the last stimulus pair they saw on the screen as quickly as possible. Participants only heard a beep if the stimulus pair was a target pair or control item. The presentation of the stimulus pairs was almost identical to that of Hartsuiker et al. (2005). The experiment started with a familiarisation phase of 20 trials after which the experimental phase began. Every stimulus pair was presented on the screen for $700 \mathrm{~ms}$ after which a blank screen of $200 \mathrm{~ms}$ followed. A beep of $400 \mathrm{~ms}$ was played in case a target pair or control item was presented. After $1000 \mathrm{~ms}$, a second beep of $400 \mathrm{~ms}$ followed. Participants were asked to pronounce the stimulus pair as quickly as possible but to make sure that they finished speaking before the heard the second beep. The next trial was presented immediately after the second beep. Responses were annotated in Praat (Boersma \& Weenink, 2016) after the experiment ended and errors were categorised in full exchanges ('hust - dunt' becomes 'dust - hunt'), partial exchanges ('hust dunt' becomes 'dust - dunt' or 'hust - hunt'), or other errors ('hust - dunt' becomes 'musk nult'). Self-repairs such as 'du ... uh ... hust - dunt' were counted as full exchanges (see Nooteboom \& Quené, 2008). 


\section{Data analysis}

Before the final data set was analysed, three participants were excluded since they answered more than $50 \%$ of the trials incorrectly. The final data set was analyzed by means of generalized linear mixed effects modelling with logit function by means of the packages car (2.0-25), lme4 (version 1.1-8), and lmerTest (version 2.0-25) in R (3.2.1) (R Core Team, 2013). This analysis allowed us to include both subject and item variability (Baayen, Davidson, \& Bates, 2008). After the fixed factors were put in the model, a model with and without random slopes was created in order to decide which factor(s) should be included as random slope. A separate model for each factor was created where that factor was the only random slope for both item (Picture) and subject (Subject) or one of the two if the model did not converge. The model with and without random slope were subsequently compared by means of an ANOVA. If the models differed significantly, the factor was included as a random slope (Barr, Levy, Scheepers, \& Tily, 2013).

\section{Results}

Three participants were not included in the final analysis since they produced more than $50 \%$ other errors. Of the 3600 responses produced in this experiment, 2652 (73.7\%) were correct, 72 were full or partial exchanges (2\%), 646 were other errors (17.9\%) and 230 were missed trials $(6.4 \%)$. The percentage of full and partial errors is in line with what has been found in previous studies. The number of correct responses was similar in L1 (1324 (73.6\%)) and in L2 (1328 (73.8\%)).

An initial analysis considered all exchanges (full and partial) in the entire data set. Because these exchanges only make up $2 \%$ of the data (while the correct answers make up $73.7 \%$ ), the graphs presented below might not always exactly match the findings of the generalized linear mixed effects models. The final model of the entire data set contained the fixed factors Context (mixed vs. non-lexical context), Outcome (lexical vs. non-lexical switch), and Language (L1 vs. L2) while the dependent variable was Correctness (correct vs. incorrect). To account for subject and item variability, subject (Subject) and item (Stimulus pair) were included in the model. No random slopes were included in the model since there was no significant difference between the models with a factor added as random slope and the model without random slopes. 


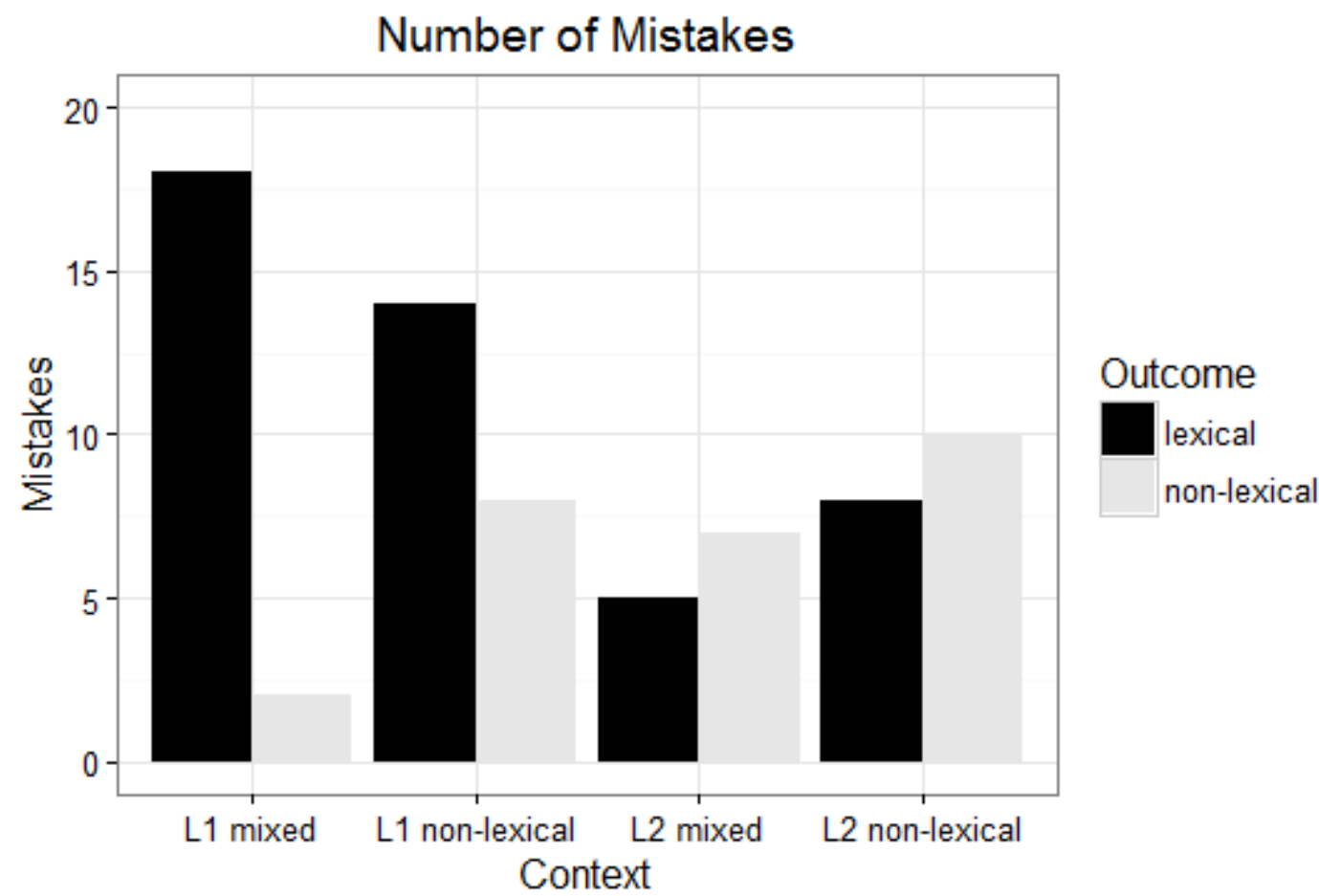

Figure 1. Graphical representation of errors made by participants in L1 and L2 divided by outcome and context. Full switches and partial exchanges are combined since only few errors were made.

Figure 1 shows the distribution of the errors of both contexts and languages. The factor Outcome was significant $(\beta=2.20, S E=0.79, z=2.79, p=.005)$ in that more lexical errors were made than non-lexical ones, thus demonstrating a lexical bias effect in the overall data. Language was also a significant factor $(\beta=1.37, S E=0.57, z=2.42, p=.02)$ : There were more errors in L1 than in L2, a rather surprising finding that will be elaborated upon in the results. There was no effect of Context $(\beta=0.29, S E=0.38, z=0.76, p=.45)$. The interaction of Outcome and Context was marginally significant $(\beta=-1.70, S E=0.88, z=-1.93, p=.05)$ : the difference between the number of lexical and non-lexical errors was marginally larger in the mixed than the non-lexical condition, suggesting a lexical bias effect. Importantly, there was an interaction effect between Outcome and Language $(\beta=-2.65, S E=1.02, z=-2.60, p=$ .009): The lexical bias effect was larger in the L1 than the L2. Indeed, Figure 1 suggests that the LBE is restricted to L1. Follow-up analyses considered the data separately for L1 and L2.

\section{L1}

The final model of the L1 data set contained the fixed factors Context (mixed vs. non-lexical context) and Outcome (lexical vs. non-lexical switch) while the dependent variable was 
Correctness (correct vs. incorrect). To account for subject and item variability, subject (Subject) and item (Stimulus pair) were included in the model. No random slopes were included in the model since there was not significant difference between the models with a factor added as random slope and the model without random slopes. The factor Outcome was significant $(\beta=2.21, S E=0.80, z=2.78, p=.005)$, demonstrating a clear LBE in L1. There was no effect of Context $(\beta=0.31, S E=0.38, z=0.83, p=.41)$. The interaction of Outcome and Context was almost significant $(\beta=-1.73, S E=0.88, z=-2.00, p=.05008)$ : the LBE was larger in the mixed than non-lexical condition.

\section{L2}

The only difference with the L1 model was that proficiency was added as a covariate in order to see whether the number of errors depend on participants' English proficiency. None of the factors and interactions were significant: (Outcome: $\beta=-0.47, S E=0.65, z=-0.73, p=.46$; Context: $(\beta=-0.58, S E=0.59, z=-0.98, p=.33)$; The Outcome $x$ Context interaction $(\beta=$ $0.10, S E=0.78, z=0.13, p=.90)$; Proficiency $(\beta=0.03, S E=0.03, z=1.03, p=.31)$.

\section{Discussion}

Experiment 1 has demonstrated that, at least in an experimental situation in which rather few L2 words are presented (12.5\%), there is a clear lexical bias effect in L1 but not in L2. In L1, the LBE was larger in the mixed context than the non-lexical context, consistent with Baars et al. (1975) and Hartsuiker et al. (2005) (note that the p-value of the crucial Context x Outcome interaction was equal to, rather than below, alpha level). The findings so far are consistent with an account according to which monitoring for lexicality affects the pattern of slips of the tongue, under the further assumption that the L2 lexicon needs to be sufficiently activated for the monitor to use L2 lexicality as a criterion. To test whether the LBE arises in L2 in a situation in which there is stronger lexical activation, Experiment 2 presented mixed blocks only. Additionally, in half of the blocks, the target items themselves existing words, whereas in the remaining blocks, they were non-existing words (as was the case in Experiment 1). As a result, two blocks of Experiment 2 are directly comparable to two blocks of Experiment 1 (i.e., the mixed, non-word target blocks), differing only in global lexical context. 


\section{Experiment 2}

\section{Methods}

Participants. 48 further participants ( 9 male / 39 female, mean age $=21.56$ ) were recruited at Ghent University. Participants were monetarily compensated. They all reported to have normal hearing, normal or corrected-to-normal sight, and not to have dyslexia. Once again, the description of the experiment mentioned that English proficiency of the participants should be relatively good. Participants were asked to perform the English LexTALE (Lemhöfer \& Broersma, 2012) in order to objectively measure their proficiency.

Stimuli. The stimuli used in this experiment were partly identical to those in Experiment 1: in particular, both the Dutch and the English mixed blocks from Experiment 1 were used here as well. The other two blocks were also mixed blocks, so that that all four blocks had the same lexical context. The only difference with the previous experiment is that the target pairs in the two new mixed blocks consisted of existing words (lexical) or nonexisting words (non-lexical). The two blocks that were identical to that of Experiment 1 still contained non-existing target pairs. Hence, the lexicality of the target word is now a distinguishing factor. Note that the amount of exposure to existing word pairs has increased to $50 \%$ (25\% English, 25\% Dutch) since all blocks are mixed blocks. Finally, the words that were part of the biasing pairs in these blocks were existing words as well. All other stimuli were identical to that of Experiment 1. The target pairs are listed in Appendix B.

Design. In contrast to Experiment 1, Context was not a factor (all contexts were mixed). The three within-subject variables were Outcome, Language, and Target lexicality (lexical or non-lexical target pair). Four stimulus blocks were created instead of eight since it was not possible to create non-existing counterparts for the existing word pairs that also resulted into existing word pairs after transposing the first consonants. Ultimately, 24 versions were created for this experiment.

Procedure. The procedure of Experiment 2 was identical to that of Experiment 1. 


\section{Results}

Of the 3840 responses produced in this experiment, 2994 (78\%) were correct, 64 were full or partial exchanges (1.7\%), 711 were other errors (18.5\%), and 71 trials were missed (1.8\%). The number of correct responses was slightly lower in L1 (1478 (77\%)) than in L2 (1516 $(81.3 \%))$.

An initial analysis considered all exchanges (full and partial) in the entire data set (Figure 2). The final model of the entire data set contained the fixed factors Target lexicality (lexical vs. non-lexical target), Outcome (lexical vs. non-lexical switch), and Language (L1 vs. L2) while the dependent variable was Correctness (correct vs. incorrect). To account for subject and item variability, subject (Subject) and item (Stimulus pair) were included as random effects in the model. No random slopes were included in the model since there was no significant difference between the models with a factor added as random slope and the model without random slopes.

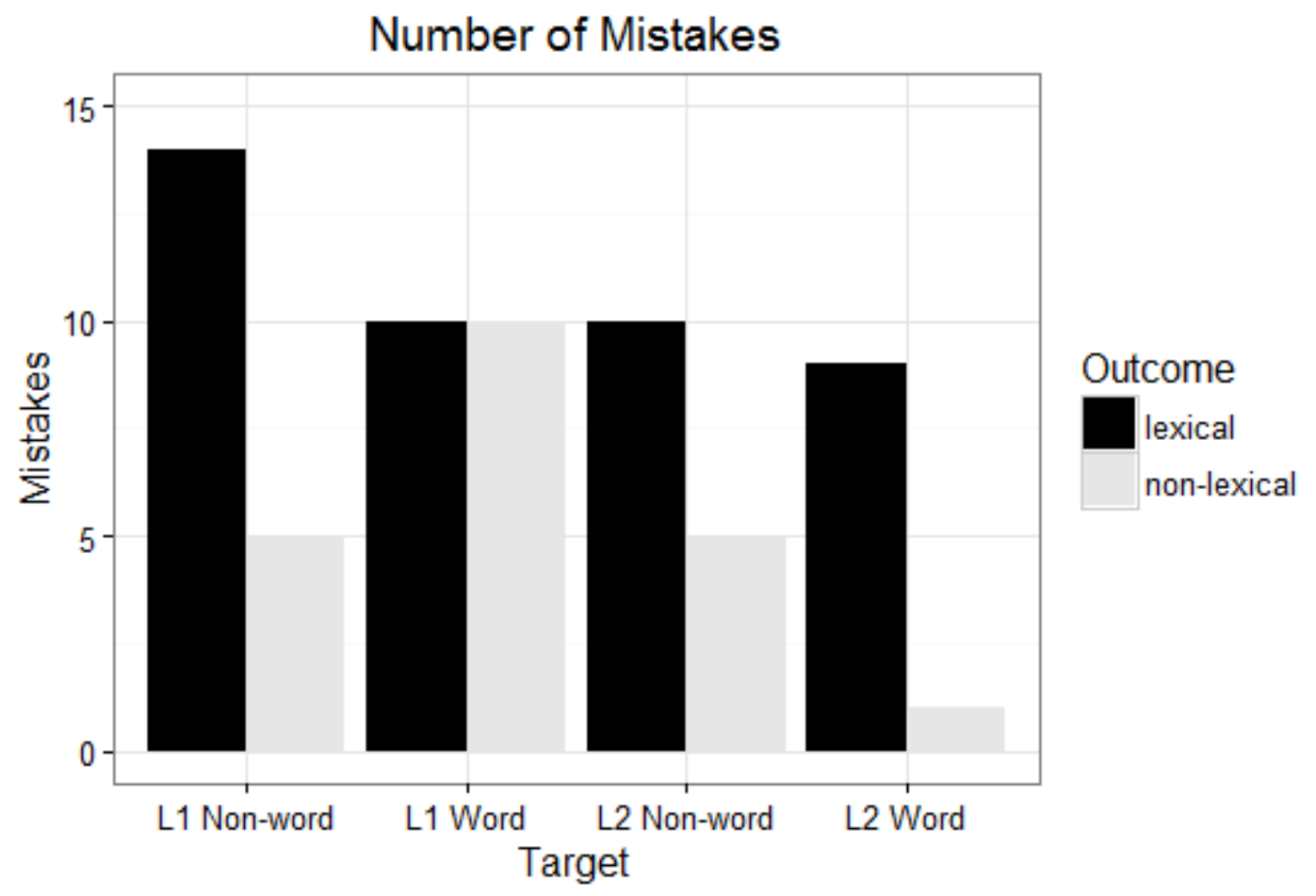

Figure 2. Graphical representation of errors made by participants in L1 and L2 divided by outcome and context. Full switches and partial exchanges are combined since only few errors were made.

Figure 2 shows the number of errors for each target type and language. Outcome was not significant $(\beta=0.95, S E=0.58, z=1.64, p=.10)$ : in other words, there was no LBE in the 
overall data. There was also no effect of Target $(\beta=0.63, S E=0.48, z=1.30, p=.19)$ or Language $(\beta=0.37, S E=0.48, z=0.77, p=.44)$. There was a marginally significant threeway interaction effect of Outcome, Target, and Language $(\beta=2.73, S E=1.46, z=1.88, p=$ .06), suggesting an LBE in both L1 and L2 for non-word pairs, but an LBE only in L2 for word pairs. To investigate this data pattern further, we ran separate analyses per language.

\section{L1}

The final model of the L1 data set contained the fixed factors Target (lexical vs. non-lexical context) and Outcome (lexical vs. non-lexical switch) while the dependent variable was Correctness (correct vs. incorrect). To account for subject and item variability, subject (Subject) and item (Stimulus pair) were included in the model as random effects. No random slopes were included in the model since there was not significant difference between the models with a factor added as random slope and the model without random slopes. Neither the main effects nor the interaction reached significance (Outcome: $\beta=0.94, S E=0.61, z=$ 1.53, $p=.13$; Target: $\beta=0.63, S E=0.53, z=1.19, p=.23$; Outcome $\mathrm{X}$ Target: $\beta=-1.09, S E$ $=0.83, z=-1.32, p=.19)$.

\section{L2}

The final model of the L2 data set contained the same variables and proficiency was added to this model in order to test whether English proficiency had an effect on the number of errors that were made. As with the L1 data set, there were no main effects or interaction effects: Outcome $(\beta=0.51, S E=0.56, z=0.91, p=.37$; Target $(\beta=0.33, S E=0.48, z=0.70, p=.49$; Proficiency: $(\beta=0.01, S E=0.02, z=0.44, p=.66)$; Outcome $\mathrm{X}$ Target: $(\beta=1.69, S E=1.20$, $z=1.41, p=.16)$.

\section{Combined Analysis}

Recall that half of the blocks in L1 and L2 were identical to each other (the mixed blocks of Experiment 1 / non-word target blocks of Experiment 2). An additional analysis was performed in which these blocks were combined, with Experiment as a factor. This was done so that the effect of language exposure could be objectively measured; The only difference between these identical blocks in Experiment 1 and Experiment 2 was the amount of exposure 
to existing word pairs. Hence, the effect of exposure can be filtered out. In the generalized linear mixed effects model, the factors Outcome, Language, and Experiment were included. The factor Experiment consisted of two levels: Experiment 1 and Experiment 2. The factor Outcome was added as a random slope for Subject (Subject) while no random slopes were included for Item (Stimulus pair).

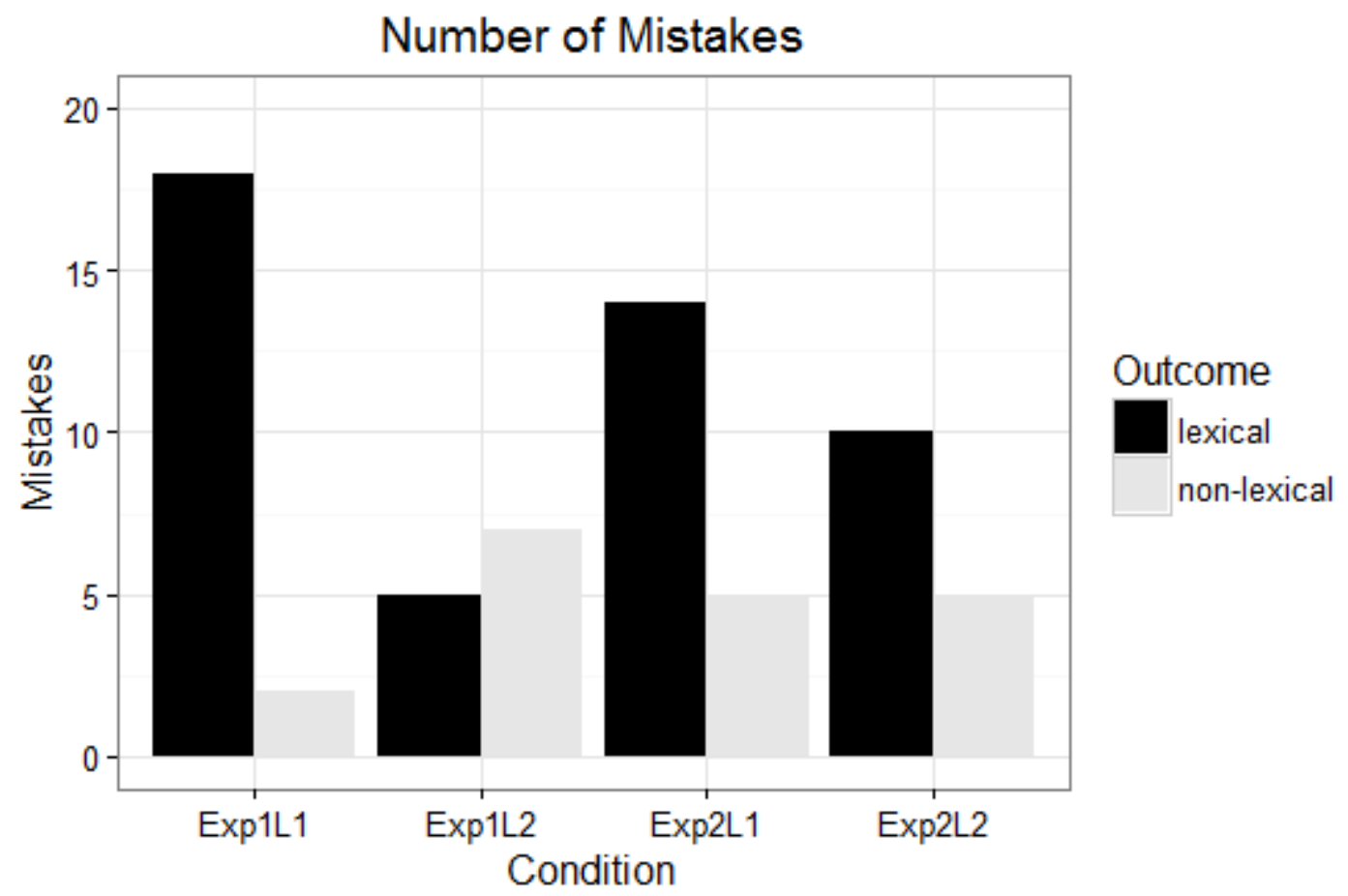

Figure 3. Graphical representation of errors made by participants in L1 and L2 divided by outcome, language, and experiment of the identical blocks. Full switches and partial exchanges are combined since only few errors were made.

Figure 3 shows the comparison of lexical and non-lexical errors between experiments and languages. The factor Outcome was significant $(\beta=4.74, S E=1.92, z=2.47, p=.01)$ : there was an LBE in the combined data set. There was also an effect of Language $(\beta=1.40, S E=$ $0.57, z=2.47, p=.01$ ), indicating that participants made more errors in L1 than L2. The interaction of Outcome and Language was also significant $(\beta=-2.85, S E=1.06, z=-2.69, p$ $=.007)$. This means that the LBE is larger in L1 than in L2. Finally, there was a marginally significant three-way interaction of Outcome, Language, and Experiment $(\beta=2.29, S E=$ $1.34, z=1.71, p=.09)$. This suggests that in Experiment 1, the LBE was limited to L1 but in Experiment 2, it occurred in both L1 and L2. 


\section{Discussion}

Unlike Experiment 1, Experiment 2 did not demonstrate an overall lexical bias effect (even though it was descriptively present in most conditions). There was, however, a marginally significant interaction effect Outcome, Target, and Language suggesting an LBE in both L1 and L2 for non-word pairs, but only in L2 for word pairs. Note that the most obvious difference with Experiment 1 was the larger number of real words in L1 and L2 that participants were exposed to in Experiment 2. By comparing errors rates from blocks with the same stimuli lists across experiments, the overall exposure effect due to the experimental setup were obtained. In this analysis, both Outcome and Language were significant, indicating an overall lexical bias effect and an L2 advantage regarding the total number of errors. The interaction effect of Outcome and Language suggests that the lexical bias effect is larger in L1 than in L2. Importantly, the marginally significant three-way interaction suggests that the LBE is limited to L1 in Experiment 1 but occurs in both languages in Experiment 2.

\section{General Discussion}

Two experiments elicited slips of the tongue in L1 and L2. Experiment 1, in which only few L2 words were presented, demonstrated a clear lexical bias effect in L1 but not in L2. Experiment 2, in which more L2 words were presented, did not demonstrate a lexical bias effect in either language. However, an analysis of a subset of the data (namely the blocks that were identical in both experiments and thus directly comparable) found a three-way interaction between Outcome, Language, and Experiment. This interaction suggests a strong lexical bias effect in Experiment 1 for L1 but not for L2 whereas Experiment 2 reveals a comparable lexical bias effect in both languages.

When considering the L2 data of Experiment 1, not a single factor was significant meaning that no lexical bias effect was found when performing the task in a second language. One might conclude that the lexical bias effect does simply not exist in L2. Yet, Costa et al. (2006) did find a lexical bias effect in the L2 of Spanish-Catalan speakers. Note, however, that the participants that Costa et al. used were far better at their L2 than the participants we used since they learned their L2 before the age of five. Furthermore, the blocks that were presented to the participants in the study of Costa et al. contained much more existing words than non-existing ones. Experiment 1 of the current study contained two English blocks where 
one block was completely devoid of existing word pairs while the other block consisted of only 50\% existing word pairs. Moreover, the target pairs were all non-existent. In Experiment 2, more Dutch and English stimulus pairs were presented and half of the target pairs contained existing word pairs. This leads to a descriptive lexical bias effect in the L2 and partly in the L1, which suggests that the lexical bias effect does appear when participants are presented with more lexical items, which is what the combined analyses indicate as well.

The marginally significant interaction of Outcome and Context indicates that the lexical bias effect is modulated by context, findings that are in line with Hartsuiker et al. (2005). This supports the notion that both feedback and monitoring are used during error detection. The fact that the interaction effect almost reaches significance in our study while it was significant in that of Hartsuiker et al. is most likely due to the effect of time pressure. In the current experiment, participants had $1000 \mathrm{~ms}$ to respond before the second beep sounded while they had $500 \mathrm{~ms}$ in the study of Hartsuiker et al. This led to fewer errors since the temporal pressure was far less in the current experiments.

Finally, the effect of Language that is observed in both Experiment 1 and the combined analysis might be explained by means of the weaker-links hypothesis. This hypothesis claims that lexical representations in the mental lexicon are weaker in L2 speakers simply because these words are used less often (see Gollan, Montoya, Cera, and Sandoval (2008) for more detail on this hypothesis). Words that are used less frequently will be have a weaker representation as well which, of course, means that more frequently used words will have stronger representations. This includes the lexical representations that arise due to switching the first two consonants. Hence, the mental representation of the switched target pairs are represented more strongly in the mental lexicon in L1, meaning that these are more likely to interfere during the SLIP task. This suggests that there is less or no interference (and therefore no lexical bias effect) in L2.

In conclusion, the amount of exposure to existing words appears to have an influence on the occurrence of the lexical bias effect in L1 and L2. Whereas the lexical bias effect was only present in L1 in Experiment 1 (where less existing words were presented), a comparable lexical bias effect was revealed in both L1 and L2 when comparing the same blocks across experiments. This indicates that more exposure to existing L2 words leads to an increase in activation of the lexical representations of the target language, thereby increasing the number of transpositions and therefore an increase in the strength of the lexical bias effect. 


\section{References}

Baars, B. J., Motley, M. T., \& MacKay, D. G. (1975). Output editing for lexical status in artificially elicited slips of the tongue. Journal of verbal learning and verbal behavior, 14(4), 382-391.

Baayen, R. H., Davidson, D. J., \& Bates, D. M. (2008). Mixed-effects modeling with crossed random effects for subjects and items. Journal of Memory and Language, 59(4), 390412. https://doi.org/10.1016/j.jml.2007.12.005

Barr, D. J., Levy, R., Scheepers, C., \& Tily, H. J. (2013). Random effects structure for confirmatory hypothesis testing: Keep it maximal. Journal of memory and language, 68(3), 255-278.

Boersma, Paul \& Weenink, David (2017). Praat: doing phonetics by computer [Computer program]. Version 6.0.28, retrieved 23 March 2017 from http://www.praat.org/

Costa, A., Roelstraete, B., \& Hartsuiker, R. J. (2006). The lexical bias effect in bilingual speech production: Evidence for feedback between lexical and sublexical levels across languages. Psychonomic Bulletin \& Review, 13(6), 972-977.

https://doi.org/10.3758/BF03213911

Gollan, T. H., Montoya, R. I., Cera, C., \& Sandoval, T. C. (2008). More use almost always means a smaller frequency effect: Aging, bilingualism, and the weaker links hypothesis. Journal of memory and language, 58(3), 787-814.

Hartsuiker, R. J., Corley, M., \& Martensen, H. (2005). The lexical bias effect is modulated by context, but the standard monitoring account doesn't fly: Related beply to Baars et al. (1975). Journal of Memory and Language, 52(1), 58-70.

https://doi.org/10.1016/j.jml.2004.07.006 
Lemhöfer, K., \& Broersma, M. (2012). Introducing LexTALE: A quick and valid Lexical Test for Advanced Learners of English. Behavior Research Methods, 44, 325-343.

Nooteboom, S., \& Quené, H. (2008). Self-monitoring and feedback: A new attempt to find the main cause of lexical bias in phonological speech errors is. Journal of Memory and Language, 58(3), 837-861. https://doi.org/10.1016/j.jml.2007.05.003

R Core Team. (2013). R: A language and environment for statistical computing. Vienna, Austria.: R Foundation for Statistical Computing,. Retrieved from http://www.Rproject.org/. 


\section{Appendix A}

$\begin{array}{llll}\text { List 1 English } & \text { List 2 English } & \text { List 3 Dutch } & \text { List 4 Dutch } \\ \text { mift - gitt } & \text { hust - dunt } & \text { dalf - karm } & \text { hers - kesp } \\ \text { veag - beax } & \text { dift - rish } & \text { weps - venp } & \text { rors - nomp } \\ \text { gail - tain } & \text { duts - nuck } & \text { zits - mins } & \text { malf - zals } \\ \text { fath - mang } & \text { yalt - sawn } & \text { kals - hast } & \text { huts - muls } \\ \text { simp - rirg } & \text { coad - roat } & \text { herl - weln } & \text { gerf - vesp } \\ \text { lelt - beft } & \text { sich - rilk } & \text { zoch - norg } & \text { herp - weks } \\ \text { yant - salm } & \text { barm - fald } & \text { huks - murn } & \text { fuid - zuif } \\ \text { dilm - rilf } & \text { dalk - wark } & \text { rong - nolk } & \text { neug - zeut } \\ \text { yelt - mell } & \text { kest - jept } & \text { dont - boch } & \text { keuk - beur } \\ \text { sump - bung } & \text { veam - beal } & \text { beus - reul } & \text { welg - venk } \\ \text { hulf - dufk } & \text { mirg - gilp } & \text { hemp - kelf } & \text { darg - kafk } \\ \text { foft - sont } & \text { lirs - wilk } & \text { vorf - korm } & \text { voem - hoen } \\ \text { dufs - nush } & \text { gaif - taip } & \text { marg - zamk } & \text { ziln - mirk } \\ \text { nesk - dext } & \text { farl - mamc } & \text { meft - herg } & \text { kams - harn } \\ \text { coag - roan } & \text { yamp - marb } & \text { gelm - verp } & \text { gork - molp } \\ \text { yark - mard } & \text { lerf - belp } & \text { gond - mort } & \text { zols - nonf } \\ \text { bilf - firp } & \text { nelm - derk } & \text { fuir - zuin } & \text { mern - helg } \\ \text { dalp - wamf } & \text { folp - sosh } & \text { neuf - zeup } & \text { vokt - komp } \\ \text { lerg - jesp } & \text { yemb - merf } & \text { keut - beug } & \text { dofs - bolf } \\ \text { ling - wimb } & \text { surk - bulm } & \text { voek - hoeg } & \text { beuf - reup }\end{array}$




\section{Appendix B}

$\begin{array}{llll}\begin{array}{l}\text { English non-words } \\ \text { hust - dunt }\end{array} & \begin{array}{l}\text { English words } \\ \text { duck - lump }\end{array} & \begin{array}{l}\text { Dutch non-words } \\ \text { dalf - karm }\end{array} & \begin{array}{l}\text { Dutch words } \\ \text { mest - berg }\end{array} \\ \text { surk - bulm } & \text { lean - real } & \text { weps - venp } & \text { kers - hesp } \\ \text { duts - nuck } & \text { must - dusk } & \text { zits - mins } & \text { maf - gat } \\ \text { yalt - sawn } & \text { push - bull } & \text { kals - hast } & \text { zoen - doek } \\ \text { lerf - belp } & \text { tail - gain } & \text { herl - weln } & \text { zalf - mals } \\ \text { sich - rilk } & \text { tell - sent } & \text { zoch - norg } & \text { dorp - wolk } \\ \text { farl - mamc } & \text { math - fang } & \text { huks - murn } & \text { muts - huls } \\ \text { lirs - wilk } & \text { felt - left } & \text { rong - nolk } & \text { werp - heks } \\ \text { kest - jept } & \text { lash - back } & \text { dont - boch } & \text { duim - ruik } \\ \text { veam - beal } & \text { bug - mud } & \text { beus - reul } & \text { ruit - buik } \\ \text { mirg - gilp } & \text { seem - reef } & \text { hemp - kelf } & \text { boog - kool } \\ \text { dalk - wark } & \text { bag - lad } & \text { vorf - korm } & \text { zaag - haal } \\ \text { gaif - taip } & \text { bump - sung } & \text { marg - zamk } & \text { velg - wenk } \\ \text { barm - fald } & \text { pig - bill } & \text { meft - herg } & \text { kaal - maas } \\ \text { yamp - marb } & \text { burn - hurt } & \text { gelm - verp } & \text { raam - taal } \\ \text { coad - roat } & \text { wish - dig } & \text { gond - mort } & \text { veeg - leen } \\ \text { nelm - derk } & \text { bark - yard } & \text { fuir - zuin } & \text { hert - merk } \\ \text { folp - sosh } & \text { wing - limb } & \text { neuf - zeup } & \text { verf - gesp } \\ \text { yemb - merf } & \text { leaf - meat } & \text { keut - beug } & \text { nors - romp } \\ \text { dift - rish } & \text { tall - walk } & \text { voek - hoeg } & \text { deeg - ween }\end{array}$


